\title{
INFECÇÃO POR Kudoa sp. NA MUSCULATURA ESQUELÉTICA DE Genyatremus luteus Blochii,1795 (PERCIFORME: HAEMULIDAE), PEIXE AMAZÔNICO
}

\author{
Ana Beatriz Mendes Amaral Ramos; Rebeca Silva de Araújo²; Anny Marysol Souza \\ Cavalcante; ; Lenize Carolina Alves Hemetério4; Edilson Rodrigues Matos ${ }^{5}$. \\ 1Universidade Federal Rural da Amazônia, Belém, Pará, Brasil, abmaramos@gmail.com \\ ${ }^{2}$ Universidade Federal do Acre, Rio Branco, Acre, Brasil, rebecasilvade@gmail.com \\ ${ }^{3}$ Universidade Federal do Pará, Belém, Pará, Brasil, anny_marysol@hotmail.com \\ 4 Universidade Federal Rural da Amazônia, Belém, Pará, Brasil, lenize.hemeterio@hotmail.com \\ ${ }^{5}$ Universidade Federal Rural da Amazônia, Belém, Pará, Brasil, edilson.matos9@gmail.com
}

RESUMO: Os mixosporídios são parasitos celulares encontrados nos diversos órgãos dos peixes de água doce ou estuarinos. Este grupo é economicamente importante por ser causador de doenças em inúmeros peixes, incluindo aqueles de valor comercial. Kudoa é destaque neste grupo por causar mioliquefação pós-mortem no pescado tornando-os impróprios para o consumo humano e, por isso, o conhecimento acerca deste gênero é de extrema importância. O objetivo deste trabalho foi descrever e caracterizar morfologicamente ogênero Kudoa Meglitsch, 1947 encontrado na musculatura esquelética em Genyatremus luteus. Foram coletados 22 espécimes de Genyatremus luteus, no município de São Caetano de Odivelas, nordeste paraense. Após a captura, os animais foram acondicionados em sacos plásticos com aeração artificial e transportados vivos ao Laboratório de Pesquisa Carlos Azevedo (LPCA), na Universidade Federal Rural da Amazônia, onde foram mantidos em aquários. Os animais foram anestesiados, sacrificados e, posteriormente, necropsiados para avaliação em microscopia de luz (ML). Fragmentos de musculatura esquelética foram retirados e esporos isolados, tetracapsulados, com corpo quadrangular ou pseudoquadrangular, determinantes do gênero Kudoa foram encontrados. Estes fragmentos contendo parasitos foram colhidos e fixados, desidratados, diafanizados e impregnados em parafina liquida. Foi realizado corte histológico e coloração em H\&E, permitindo evidenciar a formação cística no interior e entre as fibras musculares. Estudos complementares estão sendo realizados para identificação da espécie encontrada, a fim de aumentar o conhecimento sobre o estado de sanidade dos peixes da região Amazônica no estado do Pará.

PALAVRAS-CHAVE: Genyatremus luteus, Mioliquefação pós-mortem, Myxozoa. 


\title{
INFECTION Kudoa sp. IN THE SKELETAL MUSCULATURE OF Genyatremus luteus Blochii, 1795 (PERCIFORME: HAEMULIDAE), AMAZONIAN FISH
}

\begin{abstract}
Myxosporids are cellular parasites found in several organs of freshwater or estuarine fish. This group is economically important because it causes disease in countless fishes, including those of commercial value. Kudoa is prominent in this group for causing post-mortem myoliquefaction in the fish, making them unsuitable for human consumption and therefore the knowledge about this genus is of extreme importance. The aim of this work was to describe and characterize the Kudoa genus found in skeletal muscle in Genyatremus luteus. Twenty two specimens of Genyatremus luteus were collected in São Caetano de Odivelas northeast of Pará. After the capture, the animals were placed into plastic bags with artificial aeration and transported live to the Carlos Azevedo Research Laboratory (LPCA), at the Federal Rural University of Amazonia, where they were maintained in an aquarium. The animals were anesthetized, sacrificed and subsequently necropsied for examination under light microscopy (ML). Fragments of skeletal musculature were removed and isolated, tetracapsulated spores with the quadrangular or pseudo-quadrangular body, determinants of the Kudoa genus were found. These parasite containing fragments were removed and fixed, dehydrated, diaphanized and impregnated in liquid paraffin. Histological section and $H$ \& E staining were performed, allowing evidence of cystic formation within and between muscle fibers. Complementary studies are being carried out to identify the species found in order to increase the knowledge about the health status of the fish from the Amazon region in the state of Pará.
\end{abstract}

KEYWORDS: Genyatremus luteus, Mioliquefaction pós-mortem, Myxozoa.

\section{INFECCIÓN POR Kudoa sp. EN LA MUSCULATURA ESQUELÉTICA DE Genyatremus luteus Blochii, 1795 (PERCIFORME: HAEMULIDAE), PIEZA AMAZÓNICO}

RESUMEN: Los mixosporídios son parásitos celulares encontrados en los diversos órganos de los peces de agua dulce o estuarinos. Este grupo es económicamente importante por ser causante de enfermedades en numerosos peces, incluyendo aquellos de valor comercial. Kudoa es destaque en este grupo por causar mioliquefación pos- mortem en el pescado haciéndolos inapropiados para el consumo humano y, por eso, el conocimiento acerca de este género es de extrema importancia. El objetivo de este trabajo fue describir y caracterizar morfológicamente el género Kudoa Meglitsch, 1947 encontrado en la musculatura esquelética en Genyatremus 
luteus. Se recogieron 22 especímenes de Genyatremus luteus, en el municipio de São Caetano de Odivelas, nordeste paraense. Después de la captura, los animales fueron acondicionados en bolsas plásticas con aireación artificial y transportados vivos al Laboratorio de Investigación Carlos Azevedo (LPCA), en la Universidad Federal Rural de la Amazonía, donde se mantuvieron en acuarios. Los animales fueron anestesiados, sacrificados y, posteriormente, necropsiados para evaluación en microscopía de luz (ML). Los fragmentos de musculatura esquelética fueron retirados y esporas aisladas, tetracapsulados, con cuerpo cuadrangular o pseudoquadrangular, determinantes del género Kudoa fueron encontrados. Estos fragmentos que contenían parásitos fueron recogidos y fijados, deshidratados, diafanizados e impregnados en parafina líquida. Se realizó corte histológico y coloración en H\&E, permitiendo evidenciar la formación cística en el interior y entre las fibras musculares. Los estudios complementarios se están realizando para identificar la especie encontrada, a fin de aumentar el conocimiento sobre el estado de sanidad de los peces de la región Amazónica en el estado de Pará.

PALABRAS CLAVE: Genyatremus luteus, Mioliquefación pós-mortem, Myxozoa.

A região amazônica abriga uma das maiores diversidades ictiológicas do mundo (LÉVÊQUE et al., 2008; OLIVEIRA et al., 2015). Genyatremus luteus (coró ou peixe-pedra) é amplamente comercializado e apreciado na culinária paraense (BARROS et al., 2012). No ano de 2009 sua pesca gerou uma renda de 7 milhões para os estados do Pará e do Maranhão (IBAMA, 2009).

Pertence à classe Actinopterygii, à ordem Perciforme e à família haemulidae. Habitam águas costeiras, especialmente estuários e lagunas, sobre fundos de lama e areia
(CERVIGÓN, 1966; FISHER, 1978). Sua distribuição compreende regiões abaixo das Antilhas e a costa norte da América do Sul, da porção este da Colômbia para o Brasil.

G. luteus é considerada uma espécie de pequeno a médio porte, demersal e de hábitos costeiros (ESPÍRITO SANTO et al., 2005; FERNANDES et al., 2015), caracterizada como onívora, tratada como oportunista e com hábitos tipicamente bentônicos (NORLETOFILHO et al., 2012). Alimenta-se de bivalves, equinodermos, algas, crustáceos (ALMEIDA et al., 2005) e peixes menores. 
A fauna parasitária em um ser vivo pode apresentar diversos arranjos, que irão depender de fatores bióticos e fatores abióticos (EIRAS, 1994). Nos peixes há uma diversidade parasitária muito grande, devido a fatores abióticos - como qualidade da água, solo e outros - e fatores antrópicos (KUBTIZA; KUBTIZA, 2004). Porém, Luque (2004) afirma que achados ictioparasitológicos são de extrema importância, servindo como bioindicadores, avaliando o potencial zoonótico de certas espécies de parasitas e analisando a relação parasito-hospedeiro para cada espécie de peixe, principalmente aquelas que têm grande importância econômica na piscicultura e na pesca extrativista.

O grupo Myxosporidia Bütschli,1882, é eucariota, pode ser celozóico (parasitar a cavidade dos órgãos) ou histozóico (SILVA-JÚNIOR, 2012) e causa patologias denominadas de mixosporidioses (CASAL et al., 2008).

São parasitas de vários grupos, dentre eles: répteis, aves, platelmintos, mamíferos e alguns invertebrados, porém sua maior ocorrência é em peixes (KENT et al., 2001; LOM; DIKOVÁ, 2006; EIRAS, 2007; PRUNESCU et al., 2007; BARTHOLOMEW et al., 2008). Parasitam vários tecidos e órgãos, havendo relatos de que parasitam, inclusive: rins, gônada, coração, cavidade celomática, brânquias, fígado, musculatura, vesícula biliar e intestino (SCHALCH, 2002).

Entre os gêneros do grupo Myxozoa, o gênero Kudoa Meglitsch, 1947, tem importância ímpar (MANSOUR et al, 2014), pois, em humanos, há relatos de enfermidades ocasionadas por esses mixosporídios. Porém, até a ocasião não foi possível identificar a via de infecção. A suposição mais contundente sobre o processo infeccioso em humanos é de que este seja ocasionado pela via oral, ou seja, pela ingestão de alimentos infectados (MCCLELLAND et al., 1997; BOREHAM et al., 1998; MONCADA et al., 2001; OHNISHI et al., 2013).

A família Kudoidae Meglitsch,1960, tem cerca de 95 espécies descritas até 
o momento e, devido a isso, é uma das maiores famílias de mixosporidios descritas (EIRAS et al., 2014). Os parasitas do gênero Kudoa causam lesões na musculatura esquelética do hospedeiro, e após a morte deste podem tornar a carne imprópria para consumo, originando um fenômeno denominado mioliquefação pósmortem. Este efeito de lise muscular ocorre através de proteases produzidas pelo parasito para favorecer o seu desenvolvimento (EIRAS et al., 2014; MONOUR et al., 2014; OLIVEIRA et al., 2015).

Outra característica importante deste grupo é que podem formar ou não pseudocistos no local parasitado. Morfologicamente, o gênero Kudoa tem formato estrelado ou pseudoquadrado, com quatro ou mais cápsulas polares e valvas (KENT et al., 2001; CANNING; OKAMURA，2004; LOM; DYKOVÁ, 2006).

Devido a esses fatores, viu-se a necessidade de estudar parasitos em G.luteus, pois o parasitismo pode ser responsável pela diminuição ou desaparecimento de uma espécie da cadeia alimentar, sendo um fator de limitação (PERONl; HERNANDÉZ, 2011). Além disso, a relação parasitohospedeiro pode apresentar perigos para a saúde dos seres humanos, causando em alguns casos infecções alimentares ou alérgicas.

Há evidências de que o consumo de peixe infectado pelo gênero Kudoa cause sintomas alérgicos ou até mesmo estágios infecciosos no consumidor, tornando essa suposição uma justificativa para pesquisas com o parasito (MARTÍNEZ DE VELASCO et al., 2007; GRABNER et al., 2012; KAWAI et al., 2012).

O Presente trabalho descreve a infecção do tecido muscular de Genyatremus luteus, ocasionado por Kudoa sp.

Foram coletados 22 espécimes de Genyatremus luteus, popularmente conhecido como coró ou peixe-pedra (Figura 1) no estuário do município de São Caetano de Odivelas (0045'00" S ;4801'12" O).Os espécimes foram coletados entre os meses de março de 
2015 à janeiro de 2016, nos horários de 6:00 às 15 horas (dependendo da tábua da maré). Os peixes foram capturados com linha de pescar e rede de emalhar. Após a captura, os animais foram acondicionados em sacos com aeração artificial e transportados para o laboratório de Pesquisa Carlos Azevedo - LPCA/UFRA.

No local foram colocados em aquários para a posterior necropsia. Para realização desta, os animais foram anestesiados utilizando MS 222 Sigma (Sabdoz Laboratories). Observou-se o sexo, o comprimento total (C.T) e o peso de todos os animais. 0 comprimento total médio dos peixes foi de $\pm 14,572 \mathrm{~cm}$ (intervalos: 8,2 - 21 $\mathrm{cm}$ ) e o peso médio total foi de $\pm 3,08 \mathrm{~g}$ (variação: 1,93 - 6,78g).

Foram coletadas amostras das regiões epiaxial e hipoaxial da musculatura, observadas em lâminas na microscopia de luz (Figura 2). Fragmentos $(0,5 \mathrm{~cm})$ da região hipoaxial foram retirados e colocados em solução Davidson (ácido acético, álcool 95\%, formol e água destilada) por 24h, em uma proporção 10:1 (fixador e material biológico). Após as 24h o tecido foi processado, hidratado (em séries alcoólicas crescentes) e diafanizado em Xilol (álcool Xilol, Xilol I e Xilol II).

O tecido foi impregnado em parafina liquida, colocado na máquina de inclusão (TISSUE EMBEDDING CENTER MICRON EC350), e nele foram realizados cortes com $0,5 \mu m$ de espessura. Posteriormente, os tecidos foram corados através das técnicas H\&E (Hematoxilina-Eosina) e Coloração de Prata (Nitrato de Prata 10\%, hidróxido de potássio aquoso 10\% e Hidróxido de amônia aquoso 28\%). Os tecidos corados foram fotografados utilizando um microscópio óptico Zeiss Primo Star, e uma câmara de microscópio Zeiss Axio Cam ERc 5s, com software de imagem micrométrica. As medidas de esporos e cápsulas polares foram feitas em micrômetros ( $\mu \mathrm{m})$, e sob a ampliação de 1000x, de acordo com Lom e Dyková (1992). 
Figura 1. Espécie Genyatremus luteus- Peixe pedra/ Coró.

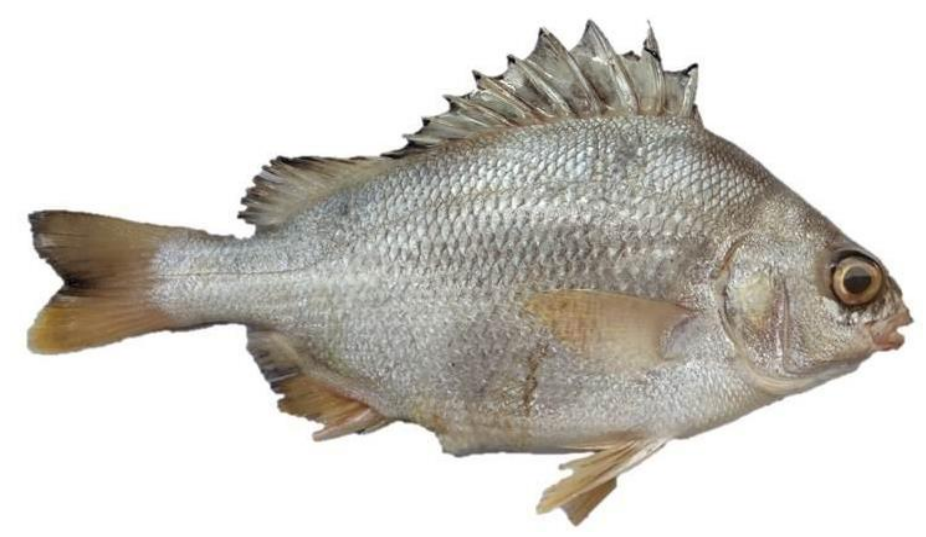

Fonte: Autor próprio.

Figura 2. Musculatura esquelética visualizada em lupa. Demonstração local coletado para posterior observação em microscopia de luz. A- Aumento de 2 X. B - Aumento de $5 X$.
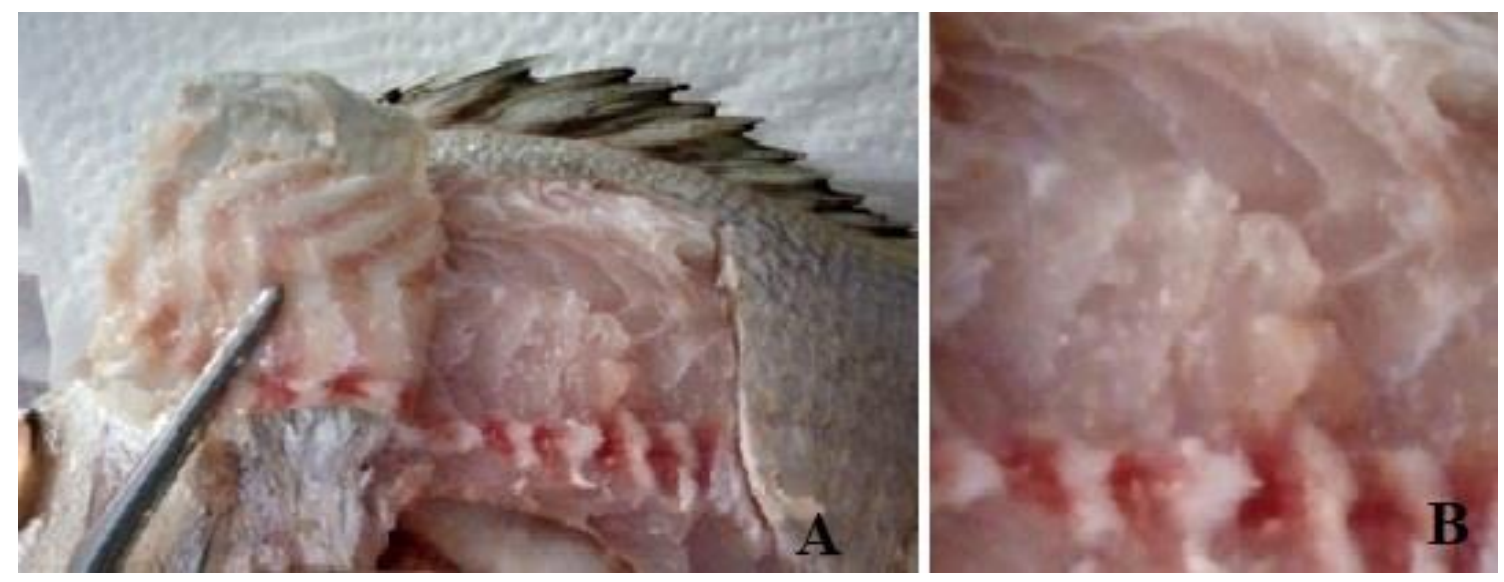

Fonte: Autor próprio.

Parasitos do gênero Kudoa são os mixosporidios mais relatados, com mais de noventa espécies descritas (EIRAS et al., 2014). Sua maior ocorrência é em peixes que habitam mares ou oceanos, porém há relatos de peixes que possuem como morada rios, como no caso da espécie 
Plagioscion squamosissimus, que foi capturada na baía do Guajará, no município de Outeiro, Belém/Pará (OLIVEIRA et al., 2015).

No Brasil existem poucas identificações de espécies do gênero Kudoa. Entre tais identificações estão presentes as seguintes espécies: Kudoa aequidens, infectando o peixe da região Amazônica Aequidens plagiozonatus (CASAL et al., 2008); Kudoa sciaenae, no peixe Stellifer minor (OLIVA et al., 1992); Kudoa crumena, na espécie Thunnus albacares (TAVARES et al., 2008); e Kudoa sp. em Mugil liza (AMATO; FREIRE, 1989), Trichiurus lepturus (ANDRADA et al., 2005; KNOFF et al., 2002), Plagioscion squamosissimus (FERREIRA et al., 2005) e Mugil platanus (KNOFF; SERRAFREIRE, 1993).

Nas observações a fresco, os parasitos foram encontrados na musculatura esquelética, mais especificamente na região hipoaxial, entre e dentro das fibras musculares, com uma prevalência parasitária de 56, $6 \%$. Este fato corrobora o relatado por Oliveira et al. (2015), em trabalho realizado na espécie Plagioscion squamosissimus, peixe amazônico. Ao comprimir o tecido em lâmina e lamínula, foram identificados pseudocistos alongados (Figura 3) no mesmo sentido da fibra muscular, que, ao serem imprensados, permitiram observar uma grande quantidade de esporos de forma estrelada ou pseudoquadrada, com quatro cápsulas polares e quatro valvas (Figura 4). A partir da morfologia descrita por Hahn (1917) o parasito foi identificado como membro do gênero Kudoa.

Sendo assim, temos a seguinte classificação taxonômica:

Filo: Cnidária

Classe: Myxozoa Grassé, 1970.

Subclasse: Myxosporea Bütschli, 1881

Ordem: Multivalvulidae Shulman, 1959

Família: Kudoidae Meglitsch, 1960

Gênero: Kudoa Meglitsch, 1947 
Houve uma grande intensidade na infecção e o número de fibras infectadas foi de alta relevância, pois em vários espécimes analisados as fibras estavam mioliquefeitas, e com várias formações de pseudocistos (figura 3), permitindo o estudo histológico da musculatura esquelética. Tal fato difere-se do relato por Eiras et al (2014), o qual descreveu a mesma ocorrência na espécie Scomberomorus brasiliensis, porém não havendo infecção nas fibras, com poucos pseudocistos no tecido e, assim, não permitindo o estudo histológico. Indo ao encontro do presente estudo estão as afirmações de Heckmann (2012), Moran et al. (1999), e, Lom e Dyková (1992), que relataram os parasitos do gênero Kudoa infectando tecidos musculares de seus hospedeiros, os quais apresentaram forma estrelada, pseudoquadrada ou arredondada na vista apical, e grande quantidade de pseudocistos da lise muscular.

Não foi possível a observação macroscópica dos pseudocistos em nenhum espécime. De acordo com Abdel-Ghaffar et al. (2012) os parasitos do gênero Kudoa formam pseudocistos que podem ser observados macroscopicamente na região muscular e causar impactos econômicos negativos.

Por outro lado, no presente estudo, a presença de mioliquefação foi visível, havendo reação inflamatória causada pelo parasito (ANDRADA et al., 2005; CASAL et al., 2008; BURGER; ADLARD, 2010; HEINIGER; ADLARD， 2012; GRABNER et al., 2012; HEINIGER et al., 2013). No estudo de Grabner et al. (2012), realizado com a espécie Paralichthys olivaceus, no mesmo sítio de infecção, relatou-se espécies do gênero Kudoa que não causaram a formação de mioliquefação visível, diferindo do presente trabalho.

Na visualização apical, os esporos tinham formato pseudoquadrado. Os dados morfométricos dos esporos de Kudoa sp. foram: comprimento na diagonal de 15,21um e largura de 12,31 um. As cápsulas polares possuíam formato piriforme, eram em número de quatro e iguais em tamanho, com comprimento de 1,78um e largura de 1,26um. O comprimento da linha de 
sutura era de 8,29um.

A análise morfométrica e morfológica do parasito do presente estudo diferiu de outras espécies estudadas do gênero Kudoa, evidenciando haver uma nova espécie. Estudos moleculares devem ser realizados para confirmar essas evidências. Além disso, este estudo registra a primeira ocorrência de parasitismo por Kudoa sp em G. luteus.

Figura 3. A - Fotomicrografia do tecido muscular com a formação de pseudocistos, a área indicada com $\left(^{*}\right)$ faz referência ao pseudocisto 10 X. B - Foto a fresco do tecido em lupa 5 X. C - Foto histológica.

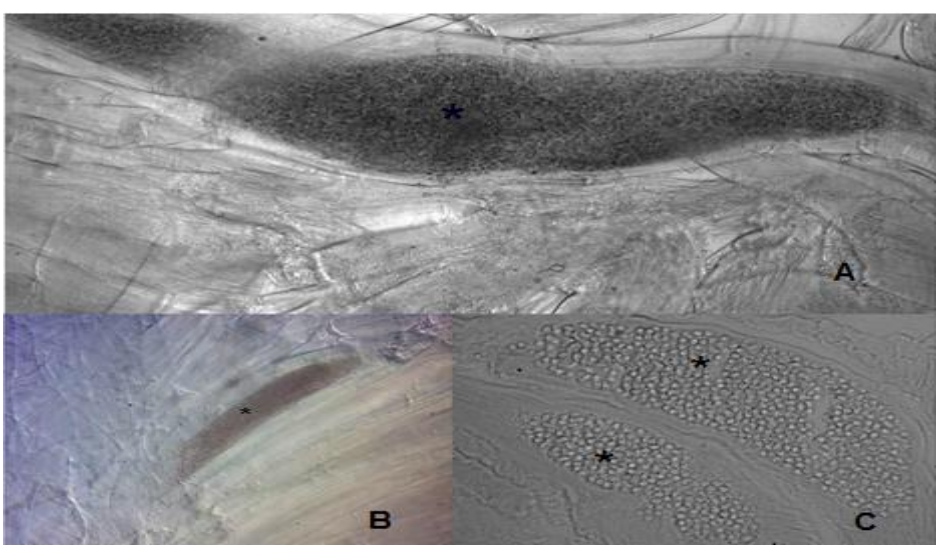

Fonte: Autor próprio.

Figura 4. Esporo de Kudoa spp. À fresco na musculatura esquelética de Genyatremus luteus $40 \mathrm{X}$.

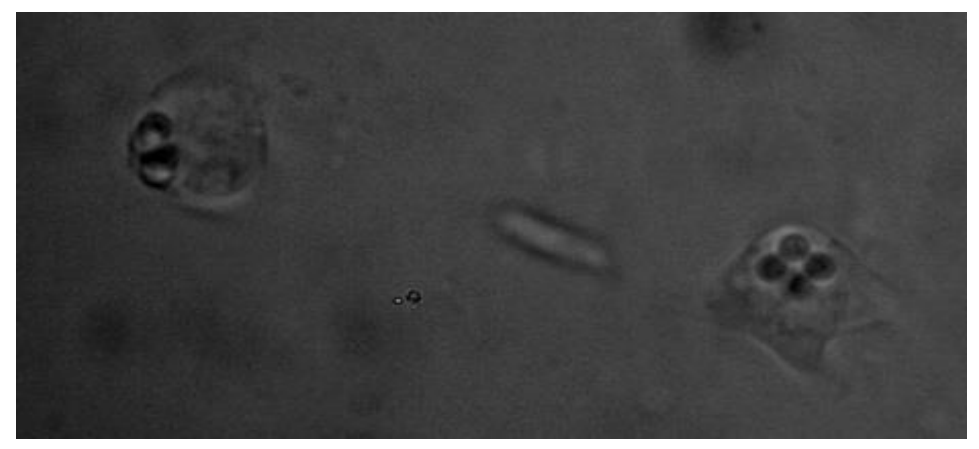

Fonte: Autor próprio. 


\section{AGRADECIMENTOS}

Á Universidade Federal Rural da Amazônia (UFRA), à Coordenação de Aperfeiçoamento de Pessoal de Nível Superior (CAPES), ao Conselho Nacional de Desenvolvimento Científico e Tecnológico (CNPq) e à Universidade Federal do Pará (UFPA).

\section{REFERÊNCIAS}

ABDEL-GHAFFAR F.; MORSY K.; MEHLHORN, H.; BASHTAR, A. R.; SHAZLY, M. A.; SAAD, A. H. First report of Kudoa species (Myxozoa: Kudoidae) infecting the spotted coral grouper Plectropomus maculates from the Red Sea. A light and ultrastructural study. Parasitol; v. 111, no.4, p. 1579-1585, 2012.

AMATO, F. F. R.; FREIRE, N. M. S. Protozoários parasitas de Mugil Liza Valenciennes, 1836 do litoral do Estado do Rio de Janeiro. In: CONGRESSO BRASILEIRO DE PARASITOLOGIA, 11., 1989, , Rio de Janeiro. Anais... Rio de Janeiro. p. 122, 1989.

ANDRADA, C. G.; TORTELLY, R.; NOGUEIRA, P. P.; ANDRADE, C. L.; LIMA, F. C. Infecção por Kudoa Meglitsch, $1947 \quad$ (Myxozoa: Multivalvulida) em musculatura esquelética de espada Trichiurus lepturos L. (Teleostei: Trichiuridae).

Parasitologia Latinoamericana, v. 60, no. 3-4, p. 150-153, 2005.
ALMEIDA, Z. S.; NUNES, J. L. S.; ALVES, M. G. F. S. Dieta alimentar de Genyatremus luteus (bloch, 1790) (TELEOSTEI, PERCIFORMES: HAEMULIDAE) na baía de São José, maranhão, Brasil. Atlântica, Rio Grande, v. 27, n. 1, p.39-47, 2005.

BARROS, D. F.; TORRES, M. F.; FRÉDOU, F. L. Ichthyofauna of the estuary of São Caetano de Odivelas and Vigia (Pará, Amazon Estuary). Biota Neotrop. v. 11, no. 2, 2012. http://www.biotaneotropica.org.br/v11 n2/en/abstra

ct?inventory+bn04111022011

BARTHOLOMEW, J. L.; ATKINSON, S. D.; HALLETT, S. L.; LOWENSTINE, L. J.; GARNER, M. M.; GARDINER, C. H.; RIDEOUT, B. A.; KEEL, M. K.; BROWN, J. D. Myxozoan parasitism in waterfowl. Internacional Journal Parasitology. v.38, p. $1199-1207,2008$.

BOREHAM, R. E.; HENDRICK, S.; O'DONOGHUE, P. J.; STENZEL, D. J. Incidental finding of Myxobolus spores (protozoa: myxozoa) in stool samples from patients with gastrointestinal symptoms. J. Clin. Microbial. v. 36, no.12, p. 3728-3730, 1998.

BURGER, M. A.; ADLARD, R. D. Four new species of Kudoa Meglitsch, 1947 (Myxosporea: Multivalvulida) from Australia with recommendations for species descriptions in the Kudoidae. Parasitology, v. 137, no. 5, p. 793-814, 2010.

CASAL, G.; MATOS, E.; MATOS, P.; AZEVEDO, C. Ultrastructural 
description of a new myxosporean parasite Kudoa aequidens sp. $\mathrm{n}$. (Myxozoa, Myxosporea), found in the sub-opercular musculature of Aequidens plagiozonatus (Teleostei) from the Amazon River. Acta Protozoologica, v. 47, no. 2, p. 135-141, 2008.

CANNING, E. U.; OKAMURA, B. Biodiversity and evolution of the Myxozoa. Adv Parasitol. v. 56, p. 43-131, 2004.

CERVIGÓN, F. Los peces marinos de Venezuela. Caracas, Fondo de Cultura Científica. p.951. 1966.

EIRAS, J. C. Elementos de ictioparasitologia. Porto, Portugal: Fundação Eng. Antônio de Almeida, 1994. p. 339.

EIRAS, J. C.; SARAIVA, A.; CRUZ, C. Synopsis of the species of Kudoa Meglitsch, $1947 \quad$ (Myxozoa: Myxosporea: Multivalvulida). Syst Parasitol. v. 87, n. 2, p. 153-180, 2014.

EIRAS, J. C.; JÚNIOR, J. P.; SAMPAIO, L.A.; ROBALDO, R.; ABREU, P. C. Myxobolus sp. can cause myoliquefaction in vivo in the host Paralichthys orbignyanus Valenciennes, 1893 (Osteichthyes, Paralichthydae). Diseases of Aquatic Organisms, v. 77, n. 3, p. 255-258, 2007.

ESPÍRITO SANTO, R. V.; ISAAS, V. J.; SILVA, L. M. A.; MARTINELLI, J. M.; HIGUCHI, H.; SAIT-PAUL, U. Peixes e Camarões do litoral bragantino, Pará, Brasil. Belém: Madam, 2005, v.1. 268p.
FERREIRA, E. S.; HOLANDA, W. R. S.; SEIXAS, L.S.; MATOS, P.; MATOS, E. Ocorrência de Kudoa sp. em Plagioscion squamosissimus (Heckel, 1840) no Estado do Pará. In CONGRESSO BRASILEIRO DE ENGENHARIA DE PESCA, 14., 2005, Fortaleza. Anais... Fortaleza. 2005. p. 89.

FERNANDES, S. C. P.; BENTES, A. B.; PEREIRA, L. J. G.; NASCIMENTO, M. S.; BENTES, B. Variação temporal da captura comercial do peixe pedra, Genyatremus luteus, desembarcado em um pólo pesqueiro da costa norte do Brasil- Península de Ajuruteua Bragança - Pa. Boletim Instituto da Pesca, São Paulo, v. 41, no. 1, p. 173 182, 2015.

FISHER, W. Species identification sheets for fishery purposes. Western Central Atlantic (Fishing Area 31). Volume IV. 1978. Publ. FAO.

GRABNER, D. S.; YOKOYAMA, $H_{\text {.; }}$ SHIRAKASHI, S.; KINAMI, R. Diagnostic PCR assays to detect and differentiate Kudoa septempunctata, K. thyrsites and K. lateolabracis (Myxozoa, Multivalvulida) in muscle tissue of olive flounder (Paralichthys olivaceus). Aquaculture.; p. 338-341: 36-40, 2012.

HAHN, C. W. On the sporozoan parasites of the fishes of Woods Hole and vicinity. III. On the Chloromyxum clupeidae of Clupea harengus (Young), Pomolobus pseudo-harengus (Young), and $P$. aestivalis (Young). J Parasitol v.4, p. $13-20,1917$. 
HECKMANN, R. A. Histopathology and fine structure of two myxosporidans, Kudoa clupeidae and Henneguya sebasta and a microsporidian glugea infecting fishes from the California, USA coast, histozoic parasites. Proc Parasitol v. 54, p. 1-25, 2012.

HEINIGER, H.; ADLARD, R. D. Host specificity and local infection dynamics of Kudoa leptacanthae n. sp. (Multivalvulida: Kudoidae) from the pericardial cavity of two Zoramia spp. (Perciformes: Apogonidae) at Lizard Island lagoon, Queensland, Australia. Parasitol Int. v. 61, no. 4, p. 697-706, 2012.

HEINIGER, H.; CRIBB, T. H., ADLARD, R. D. Intra-specific variation of Kudoa spp. (Myxosporea: Multivalvulida) from apogonid fishes (Perciformes), including the description of two new species, K. cheilodipteri $n$. sp. and $K$. cookii n. sp., from Australian waters. Syst Parasitol. v. 84, no. 3, p. 193- 215, 2013.

IBAMA. Autorizações e Licenças para Fins Científicos e Didáticos - SISBIO. Disponível em <http://servicos.ibama.gov.br/cogeq/i ndex. php?id menu=106 > 2009.

KAWAI, T.; SEKIZUKA, T.; YAHATA, Y.; KURODA, M.; KUMEDA, Y.; IIJMA, Y. Identification of Kudoa septempunctata as the causative agent of novel food poisoning outbreaks in Japan by consumption of Paralichthys olivaceus in raw fish. Clin Infect Dis. v. 54, no. 8, p. 1046-1052, 2012.
KENT, M. L.; ANDREE, K. B.; BARTHOLOMEW, J.L.; EL-MATBOULI, M.; DESSER, S. S.; DEVLIN, R. H.; FEIST, S. W.; HEDRICK, R. P.; HOFFMANN, R. W.; KHATTRA, J.; HALLETT, S. L.; LESTER, R. J. G.; LONGSHAW, M.; PALENZEULA, O.; SIDDALL, M. E.; $X I A O, C$. Recent Advances in Our Knowledge of the Myxozoa. J. Eukaryot. Microbiol. v. 48, no. 4, 2001.

KNOFF, M.; SERRA-FREIRE, N. M. Protozoários parasitos de Mugil platanus Günther, 1880 do litoral do Estado do Rio de Janeiro, Brasil. Revista Brasileira de Parasitologia Veterinária. v. 2, no. 1, p. 25-28, 1993.

KNOFF, M.; SÃO CLEMENTE， S. C.; LIMA, F. C.; PINTO, R. M.; GOMES, D. C. Infecção por Kudoa, Meglitsch, 1947 (Myxozoa: Multivalvulida) em musculatura esquelética de espada Trichiurus lepturus L. (Teleostei: Trichiuridae). In: ENCONTRO BRASILEIRO DE PATOLOGISTAS DE ORGANISMOS AQUÁTICOS, 7., 2002, Foz do Iguaçú. Anais... Foz do Iguaçú. 2002. p. 157.

LÉVÊQUE, C.; OBERDORFF, T.; PAUGY, D.; STIASSNY, M. L. J.; TEDESCO, P.A. Global diversity of fish (Pisces) in freshwater. Hydrobiologia. v. 595, p. 545-567, 2008.

LOM, J.; DYKOVÁ, I. Myxozoan genera: definition and notes on taxonomy, lifecycle terminology and pathogenic species. Folia Parasitol (Praha). v. 53, no. 1, p. 1-36, 2006. 
LOM, J.; DYKOVÁ, I. Development in aquaculture and fisheries science. Protozoários Parasitas de Peixes. Amsterdam: Elsevier. v. 26, p. 315, 1992.

LUQUE, J. L. Biologia, epidemiologia e controle de parasitas de peixes. Congresso Brasileiro de Parasitologia Veterinária \& I Simpósio LatinoAmericano de Ricketisioses, 130; Anais Ouro Preto, MG, 2004.

MANSOUR, L.; THABET, A.; CHOURABI, K.; HARRATH, A. H.; GTARI, M.; AL OMAR S. Y. Kudoa azevedoi n. sp. (Myxozoa, Multivalvulida) from the oocytes of the Atlantic horse mackerel Trachurus trachurus (Perciformes, Carangidae) in Tunisian coasts. Parasitol Res. v. 112, no. 4, p. 1737-1747, 2014.

MARTíNEZ, D. E.; VELASCO, G.; RODERO, M.; CHIVATO, T.; CUÉLLAR, C. Seroprevalence of anti-Kudoa sp. (Myxosporea: Multivalvulida) antibodies in a Spanish population. Parasitol Res. v. 100, no. 6, p. 1205-1211, 2007.

MORAN, J. D. W.; WHITAKER, D. J.; KENT, M. L. A review of the myxosporean genus Kudoa Meglitsch, 1947, and its impact on the international aquaculture industry and commercial fisheries. Aquaculture. v. 172, no. 1-2, p. 163-196, 1999.

MCCLELLAND, R. S.; MURPHY, D. M.; CONE, D. K. Report of Spores of Henneguya salminicola (Myxozoa) in Human Stool Specimens: Possible Source of Confusion with Human
Spermatozoa. J. Clin. Microbiol. p. 2815-2818, 1997.

MONCADA, L. I.; LÓPEZ, M. C.; MURCIA, M. I.; NICHOLLS, S.; LÉON, F.; GUÍO, O. L.; CORREDOR, A. Myxobolus sp., another opportunistic parasite in immunosuppressed patients? J. Clin. Microbiol. v. 39, n. 5, p. 1938-1940, 2001.

NOLETO-FILHO E. M.; YAURI W. L. M.; LUVIZOTTO-SANTOS R. Captura de reprodutores de peixe-pedra Genyatremus luteus (block, 1797) (pisces: haemulidae) e manutenção em sistema fechado. Boletim do laboratório de hidrobiologia. v. 25, no. 1, p. 55-60. 2012.

OLIVA, M.; LUQUE, J. L.; TERAN, L.; LLICAN, L. Kudoa sciaenae (Myxozoa: Multivalvulidae) cysts distribution in the somatic muscles of Stellifer minor (Tschudi, 1844) (Pisces: Sciaenidae). Memorias do Instituto Oswaldo Cruz. v. 87, no. 1, p. 33-35, 1992.

OLIVEIRA， J. C.; VELASCO, M; SANTOS, P. F. S.; SILVA, J. M. V; SÃO CLEMENTE, S. C.; MATOS, E. Infecção por Kudoa spp. (Myxozoa) na musculatura de Plagioscion squamosissimus (Sciaenidae) da região amazônica, Brasil. J. Vet. Parasitol. Jaboticabal, v. 24, n. 2, p. 235-240, abr.-jun. 2015.

OHNISHI, T.; KIKUCHI, Y.; FURUSAWA, H.; KAMATA, Y.; SUGITA-KONISHI, Y. Kudoa septempunctata invasion increases the permeability of human intestinal epithelial monolayer. 
Foodborne Pathog. Dis. v. 10, no. 2, .137-142, 2013.

PERONI, N.; HERNANDÉZ, M.I.M. Ecologia de Populações e Comunidades. $\quad$ CCB/EAD/UFSC: Florianópolis. 2011. 103p e 104p.

PRUNESCU, C. C.; PRUNESCU, P.; PUCEK, Z.; LOM, J. The first finding of myxosporean development from plasmodia to spores in terrestrial mammals: Soricimyxum fegati gen. et sp. n. (Myxozoa) from Sorex araneus (Soricomorpha). Folia Parasitol. v. 54, p.159-164, 2007.

SCHALCH, S. H. C. Apreciação da fauna ictioparasitária em pesqueiro tipo pesque-pague do município de guariba-sp. Dissertação (Programa de Pós- Graduação em Aqüicultura, do Centro de Aqüicultura da UNESP) São Paulo, Jabuticabal, 2002.

SILVA - JUNIOR, A. C. S. Myxosporidiose em peixes de água doce. Estação Científica (UNIFAP). Macapá, v. 2, n. 2, p. 25-39, 2012.

TAVARES, L. E. R.; LUQUE, J. L.; ELISEI, C.; SOARES, C. O.; ARAÚJO, F. R.; ROSINHA, G. M. S.; SANCHES, C. C.; PERDIGÃO, S. F. Ocorrência de Kudoa crumena (Myxozoa: Myxosporea) parasitando Thunnus albacares (Perciformes: Scombridae) no litoral do Estado de São Paulo, Brasil. In:ENCONTRO BRASILEIRO DE PATOLOGISTAS DE ORGANISMOS AQUÁTICOS, 10., 2008, Búzios. Anais... Búzios. p. 185. 